\title{
Satietogenic Protein from Tamarind Seeds Decreases Food Intake, Leptin Plasma and CCK-1r Gene Expression in Obese Wistar Rats
}

\author{
Izael S. Costa ${ }^{a} \quad$ Amanda F. Medeiros $^{b}$ Fabiana M.C. Carvalho ${ }^{b}$ \\ Vanessa C.O. Lima ${ }^{b}$ Raphael P. Serquiz ${ }^{b}$ Alexandre C. Serquiz ${ }^{c}$ \\ Vivian N. Silbiger a, d Raul H. Bortolin ${ }^{d}$ Bruna L.L. Maciel ${ }^{a}$ \\ Elizeu A. Santos ${ }^{a}$ Ana H.A. Morais ${ }^{a}$ b \\ aNutrition Postgraduate Program, Center for Health Sciences, Federal University of Rio \\ Grande do Norte, Natal, Brazil; ${ }^{b}$ Biochemistry Postgraduate Program, Biosciences Center, \\ Federal University of Rio Grande do Norte, Natal, Brazil; ' Nutrition Curse, University Center \\ of Rio Grande do Norte, Natal, Brazil; ${ }^{d}$ Department of Clinical and Toxicological Analysis, \\ Center for Health Sciences, Federal University of Rio Grande do Norte, Natal, Brazil
}

\author{
Keywords \\ Cholecystokinin - Tamarindus indica L. · CCK-2R gene - PCSK1 gene · Pre-Pro-CCK gene · \\ ob gene
}

\begin{abstract}
Objective: This study evaluated the effect of a protein, the isolated Trypsin Inhibitor (TTI) from Tamarindus indica L. seed, as a CCK secretagogue and its action upon food intake and leptin in obese Wistar rats. Methods: Three groups of obese rats were fed 10 days one of the following diets: Standard diet $\left(\right.$ Labina $\left.{ }^{\circledR}\right)+$ water; High Glycemic Index and Load (HGLI) diet + water or HGLI diet + TTI. Lean animals were fed the standard diet for the 10 days. Food intake, zoometric measurements, plasma CCK, plasma leptin, relative mRNA expression of intestinal CCK-related genes, and expression of the $o b$ gene in subcutaneous adipose tissue were assessed. Results: TTI decreased food intake but did not increase plasma CCK in obese animals. On the other hand, TTI treatment decreased $C C K-1 R$ gene expression in obese animals compared with the obese group with no treatment $(p=0.027)$. Obese animals treated with TTI presented lower plasma leptin than the non-treated obese animals. Conclusion: We suggest that TTI by decreasing plasma leptin may improve CCK action, regardless of its increase in plasma from obese rats, since food intake was lowest.

(c) 2018 The Author(s)

Published by S. Karger GmbH, Freiburg
\end{abstract}


Costa et al.: Satietogenic Protein from Tamarind Seeds Decreases Food Intake, Leptin Plasma and CCK-1r Gene Expression in Obese Wistar Rats

\section{Introduction}

Obesity is considered a worldwide epidemic, characterized by excessive accumulation of body fat due to hyperplasia and/or hypertrophy of fat cells [1]. For the complex genetic-environmental etiology, obesity has a range of specific pathological consequences. It can cause disorders in the hormonal metabolism, with the appearance of most different diseases such as arterial hypertension, atherosclerosis, carcinomas, type 2 diabetes, obesity hypoventilation syndrome, pulmonary embolism, heart failure, infertility, and propensity for falls [2, 3].

A close relationship between diet and the hormonal metabolism is involved in the control of hunger and satiety [4]. The presence of food in the gastrointestinal tract contributes not only to appetite modulation but also to the regulation of energy intake and metabolism, mediated by various hormones. In this sense, the gastrointestinal tract presents different peptide-secreting cells. Among the important peptides secreted by these cells is pre-procholecystokinin (pre-pro-CCK), which by the action of the serine endopeptidase proprotein convertase subtilisin/kexin (PCSK) transforms it into its different active forms [5, 6].

The active forms of CCK differ in the number of amino acids in their structure and are found in the plasma, gastrointestinal tract, and brain [6-8]. They act at these sites by means of specific receptors, such as type $1 \mathrm{CCK}$ receptor (CCK-1R or CCKAR) in the gastrointestinal tract, and type 2 CCK receptor (CCK-2R or CCKBR) in the brain [9]. The active isoforms of CCK, when binding to the CCK-1R present in the intestine and vagal afferent nucleus (VAN), send signals of activation via the vagus nerve to the nucleus of the solitary tract, thus activating the anorectic neuropeptides $\alpha$-MSH and CART that induce the sensation of satiety [9].

Another hormone involved in modulating appetite in the long term is leptin, which is secreted by adipocytes, is responsible for the control of food intake via acting on neuronal cells of the hypothalamus. This action of leptin, as well as that of CCK, promotes the reduction of food intake and the increase in energy expenditure, thus also regulating neuroendocrine function and metabolism of carbohydrates and fats [10].

The actions of CCK and leptin have been studied in satiety, with research demonstrating that the effects of these hormones may vary when considering eutrophic and obese experimental models or humans $[11,12]$.

McLaughlin et al. [13-15], in their satiety studies, have shown that the increase in food intake of obese Zucker rats might probably be due to CCK resistance. Concerning leptin, although obese individuals present high concentrations of this hormone since it is directly proportional to the number of adipocytes, no reduction in appetite was observed, which also suggests a resistance condition [16].

Studies have found that CCK also has synergistic and functional activity in the secretion of other hormones, causing increase or inhibition of important peptides related to satiety, such as leptin or ghrelin, thus raising satiety $[17,18]$. Additionally, in obesity, it was observed that the increase in plasma leptin concentrations caused a reduction in the sensitivity of CCK receptors in the VAN [19].

In addition, Barrachina et al. [20] and Matson et al. [21] suggest a functional synergistic interaction between leptin and CCK, and strategies to reduce the effects of leptin in resistant obese individuals seem to be a way to improve the action of CCK in reducing weight gain.

Experimental models have been used to study obesity, especially those with genetically susceptible animals $[22,23]$. Although genetic mutations cause obesity in animals, obesity in humans is not only genetically determined [24]. In this sense, diet-induced obesity models (DIO) may have a great value, given its similar etiology to human obesity [25, 26].

As hormones discussed above present a clear relationship with the genesis of obesity, studies with molecules that act contributing to their better functioning are essential. Bioactive proteins, such as trypsin enzyme inhibitors, have been studied, showing beneficial health 
Costa et al.: Satietogenic Protein from Tamarind Seeds Decreases Food Intake, Leptin

effects related to the modulation of protein-mediated responses [27]. In nutrition, studying the anti-obesity and/or satiety potential of substances or molecules present in food is of great importance, given the relevance that obesity presents for human health.

Recent research by our group demonstrated that an isolated trypsin inhibitor from Tamarindus indica L. seed (TTI) presents anti-obesity and anti-inflammatory activities [28, 29]. Ribeiro et al. [28] analyzed the influence of TTI in an experimental model of satiety and found that the inhibitor was able to reduce food intake and weight gain of eutrophic animals, possibly by raising plasma CCK. Carvalho et al. [29] tested TTI activity in obese animals with metabolic syndrome and found that there was a decrease in food consumption and tumor necrosis factor alpha (TNF- $\alpha$ ), without reduction of weight gain; however, plasma CCK was not analyzed.

The classic study by Spannagel et al. [30] described pancreatic proteases that inhibit this CCK secretion in the intestine due to proteolytic inactivation of a CCK-releasing peptide. The trypsin-sensitive luminal CCK-releasing factor (LCRF) functions as an intraluminal regulator of intestinal. Thus, when pancreatic proteases are inhibited, LCRF remains active and stimulates CCK secretion.

Apart from these, few types of research attempted to analyze the effect of substances upon CCK in the context of obesity treatment, evaluating their features in other important hormones involved in the control of hunger and satiety. Studies with trypsin inhibitors that act as CCK secretagogues have confirmed their action on peripheral and central appetite control only in eutrophic conditions [28, 31-34].

In this study we tested the effect of TTI, a recognized CCK secretagogue in lean animals [28, 31-34], on food intake, nutritional status assessment, expression of intestinal CCKrelated genes, and CCK plasma concentrations as well as on the expression of $o b$ gene and leptin plasma concentrations in obese rats.

\section{Material and Methods}

\section{Tamarind Seeds}

Tamarind was obtained and botanically identified by the Brazilian Institute of the Environment and Renewable Natural Resources (IBAMA)seed bank in Natal, RN, Brazil, and its seeds were obtained by removing them from the interior of the fruit. The seeds were kept at ambient temperature $\left(23-25^{\circ} \mathrm{C}\right)$ and humidity of $50 \pm 5 \%$.

\section{Animals}

Male adult Wistar rats, weighing around $400 \mathrm{~g}$, obese according to the Lee Index ( $\geq 300)$ [35] comprise the experimental group. Obesity was previously induced using the high glycemic index and load diet (HGLI diet) in rats with 4 weeks of age for 17 weeks. Male adult lean Wistar rats were used as controls in the experiment. All animals were kept under standard lighting conditions (12 h light / $12 \mathrm{~h}$ dark); temperature $\left(23-25^{\circ} \mathrm{C}\right)$ and humidity $(50 \pm 5 \%)$; receiving water and food ad libitum.

Experiments were performed in accordance with the Laboratory Animals Care and Use Guide of the National Institutes of Health and after approval by the Ethics Committee on the Use of Animals of Potiguar University (CEUA - UnP) under the protocol number 012/2015.

Diets

Diets used in this study were Labina produced by Purina ${ }^{\circledR}$, and the HGLI diet - glycemic index 77.6; glycemic load 38.8 - was produced by our group using condensed milk, sugar and Labina ${ }^{\circledR}$ (1:0.2:1), according to the methodology described by Carvalho (unpublished results). The HGLI diet was the same used to induce and maintain obesity in the experimental animals.

The methodology was established in the Laboratory of Chemistry and Function of Bioactive Proteins (LQFPB) at Federal University of Rio Grande do Norte State, Brazil, and adapted by Carvalho et al. [29]. 
Costa et al.: Satietogenic Protein from Tamarind Seeds Decreases Food Intake, Leptin

Plasma and CCK-1r Gene Expression in Obese Wistar Rats

Tamarind seeds were peeled from the cotyledon and fine-grained to a flour (40 mesh). Then, the protein fractions were extracted using different saturation ranges (F1: 0-30\%; F2: 30-60\%; F3: 60-90\%) of ammonium sulfate. The protein fraction saturated at $30-60 \%$ of ammonium sulfate (F2), presented the highest anti-tryptic activity and was subjected to an enrichment process by affinity chromatography on a trypsin-sepharose column (GE Health Care, Waukesha, WI, USA), according to the methodology described by Carvalho et al. [29].

Protein fractions obtained by affinity chromatography were dialyzed against water, lyophilized, and subjected to trypsin inhibition assays, using $1.25 \mathrm{mmol} / \mathrm{l}$ BApNA as substrate, as described by Kakade et al. [36]. Protein was determined according to Bradford [37] using bovine serum protein (BSA) as standard.

The electrophoresis was performed to confirm the isolation of TTI as described by Laemmli [38]. The gel was subjected to a constant voltage with $50 \mathrm{~V}$ in the first hour; and after that, voltage was increased to $150 \mathrm{~V}$ until the end of the run. The gel was then submerged in a solution of distilled water ( $30 \mathrm{~mL}$ ), acetic acid $10 \%$ (5 mL), and methanol $(20 \mathrm{~mL})$. After $30 \mathrm{~min}$, it was withdrawn from the fixative solution and stayed overnight in a dye solution composed of methanol $(10 \mathrm{~mL})$ and colloidal Coomassie Blue $(40 \mathrm{~mL})$.

\section{Experimental Design}

Obese Wistar rats were individually and randomly distributed into three groups $(n=5)$. Additionally, five lean Wistar rats were selected to compose a fourth group. All groups had five days of adaptation to establish the conditions of the experiment and pattern of food consumption of each animal. On the first and last day of the experiment, nutritional status assessment (Lee index) and food intake were evaluated. Animals were then submitted for 10 days to one of the following diets and treatments:

1. Lean group/standard diet: lean animals receiving standard diet $+1 \mathrm{~mL}$ of water by gavage.

2. Obese/HGLI diet: obese animals receiving HGLI diet $+1 \mathrm{~mL}$ of water by gavage, i.e. obese animals with no treatment;

3. Obese/standard diet: obese animals receiving standard diet $+1 \mathrm{~mL}$ of water by gavage, i.e. obese animals with standard treatment;

4. Obese/HGLI diet plus TTI: obese animals receiving HGLI diet $+1 \mathrm{~mL}$ of TTI ( $25 \mathrm{mg} / \mathrm{kg})$ by gavage i.e. obese animals receiving TTI as treatment.

All diets were orally given to animals, while water and TTI were administered by oral gavage at the same time over a period of 10 days. Animals fasted $6 \mathrm{~h}$ before oral administration of diets. On the 11 th day of the experiment, animals fasted for 8-12 h before the diet was given and after $1 \mathrm{~h}$ from gavage, the rats were anesthetized with $250 \mathrm{mg}$ of tiletamine (hydrochloride) and $250 \mathrm{mg}$ of zolazepam (hydrochloride) and then euthanized for collection of blood, gut, and subcutaneous fat.

Food Intake and Nutritional Status Assessment

Food intake was evaluated $1 \mathrm{~h}$ after diet administration. The diets were weighed before and after treatment. Animals fasted $6 \mathrm{~h}$ before oral administration of diets. The initial food intake (day 1) for each animal was considered the mean of the 5 days before treatment and the final food intake the mean of the 10 days of the treatment (day 10).

The zoometric measurements for nutritional status assessment were done on the first day of the treatment before the oral administration of the diets and on the last day of treatment $1 \mathrm{~h}$ after treatment administration. The Lee index was calculated according to Bernardis and Patterson [35] by the relation between the cubic root of the body weight in grams divided by the naso-anal length in centimeters, with a cut-off value $\geq 300$ for the diagnosis of obesity. All measures were conducted by trained researchers, aiming to meet the criteria of scientific authenticity, as recommended by Novelli et al. [39].

\section{Plasma CCK and Leptin Concentrations}

Plasma CCK and leptin were determined on the 11th day of the experiment. Blood was collected by the hepatic portal vein, and the plasma was separated by centrifugation at 3,000 rpm for $15 \mathrm{~min}$ at $4{ }^{\circ} \mathrm{C}$. Plasma was used for the determination CCK and leptin according to the manufacturers' recommended protocol. CCK was determined by immunoassay with Phoenix ${ }^{\circledR}$ Kit (EK-069-04; Phoenix Pharmaceuticals, Inc., Burlingame, CA 94010, USA), while leptin was assayed using the Leptin ELISA Rat Kit (Millipore ${ }^{\circledR}$-EZRL-83K; Merck KGaA, Darmstadt, Germany).

Relative mRNA Expression of Intestinal CCK-Related Genes and Subcutaneous Adipose Tissue ob Gene

The evaluation of relative mRNA expression of intestinal CCK-related genes and the $o b$ gene in subcutaneous adipose tissue was done on the 11th day of the experiment. 
Costa et al.: Satietogenic Protein from Tamarind Seeds Decreases Food Intake, Leptin Plasma and CCK-7r Gene Expression in Obese Wistar Rats

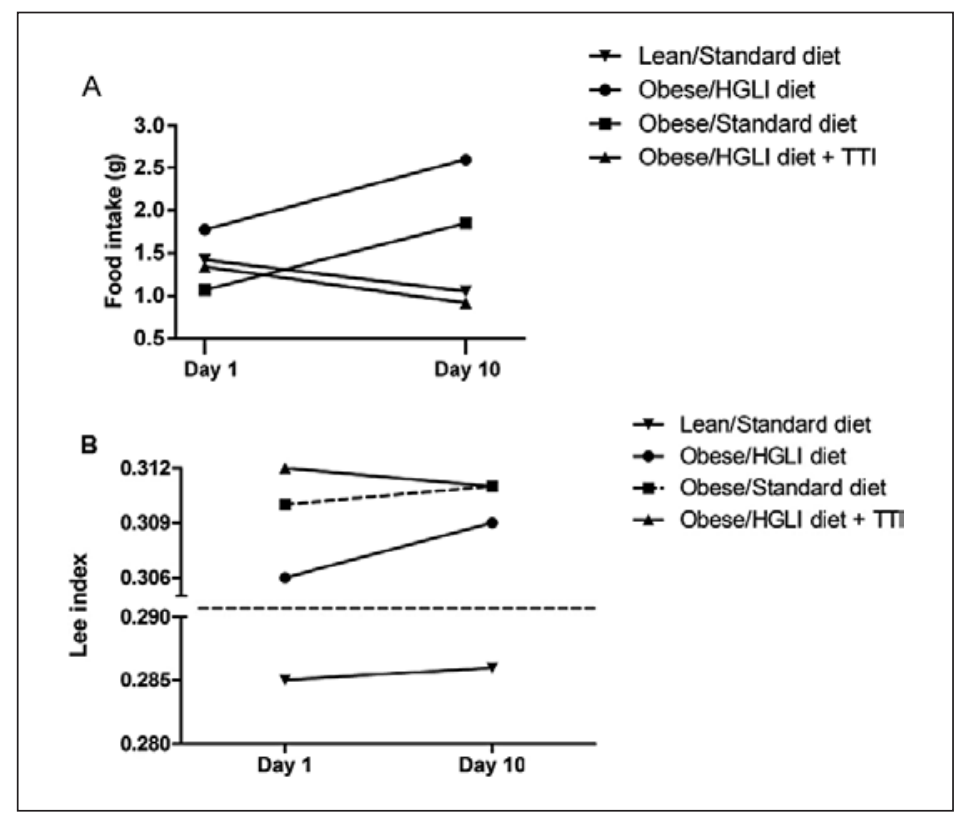

Fig. 1. Food intake and Lee index of Wistar rats in the four groups during the 10-day experiment. A) The initial food intake (day 1) for each animal was considered the mean of the 5 days before treatment and the final food intake the mean of the 10 days of the treatment (day 10). Kruskal-Wallis with Dunn's post-hoc test, $p>$ 0.05 . B) The zoometric measurements were done on the first day of the treatment and on the last day. The dashed line indicates the cut-off value for obesity, according to the Lee index $(\geq 0.300)$. Two-way ANOVA with Dunn's post-hoc test, $p>0.05$. Groups: standard diet $+1 \mathrm{~mL}$ of water by gavage (lean/standard diet); high glycemic index and load diet $+1 \mathrm{~mL}$ of water by gavage (obese/HGLI diet); standard diet $+1 \mathrm{~mL}$ water by gavage (obese/standard diet); high glycemic index and load diet $+1 \mathrm{~mL}$ of TTI at $25 \mathrm{mg} / \mathrm{kg}$ by gavage (obese/ HGLI diet + TTI). HGLI diet: Mixture composed of Labina ${ }^{\circledR}$, condensed milk and sugar (1:1:0.21); Standard diet: Labina ${ }^{\circledR}$ chow. TTI, Tamarindus indica L. seed-isolated trypsin inhibitor.

The first portion of the small intestine and the subcutaneous fat was collected, and total RNA was extracted using TRIzol ${ }^{\circledR}$ reagent (Thermo Fisher Scientific, Wilmington, DE, USA), from $100 \mathrm{mg}$ of fresh tissue sprayed in crucibles with purified liquid nitrogen, using the Mini PureLink ${ }^{\circledR}$ RNA module (Thermo Fisher Scientific), according to the manufacturer's protocol.

Total RNA quantification was done with $1 \mu \mathrm{L}$ of total RNA sample using a NanoDrop ND-2000 UV-Vis spectrophotometer (Thermo Fisher Scientific).

cDNA synthesis was performed from the total RNA using the High-Capacity cDNA Reverse Transcription Kit (Thermo Fisher Scientific) according to the manufacturer's protocol in a MyCycler ${ }^{\mathrm{TM}}$ thermocycler (BioRad, Philadelphia, PA, USA).

RT-qPCR was performed for the following genes: pro hormone convertase-1 (PCSK1, Rn00567266_m1), pre-pro-CCK (CCK, Rn005663215_m1), CCK-1R (CCKAR, Rn00562164_m1), CCK-2R (CCKBR, Rn00565867_ m1), leptin ob (Lep, Rn00565158_m1) and glyceraldehyde-3-phosphate dehydrogenase (GAPDH, Rn01775763_g1), all from Thermo Fisher Scientific, using the TaqMan assay. RT-qPCR assays were done using a real-time 7500 fast PCR system (Applied Biosystems, Foster City, CA, USA). The relative mRNA expression was calculated using the $2^{-\triangle \triangle C T}$ method normalized for GAPDH gene, according to Livak and Schmittgen [40], and results are presented as fold changes compared to the mean values of the lean control group.

\section{Statistical Analysis}

The sample size was calculated according to the difference between the treatments considered significant $(25 \%)$ and the variation coefficient (10\%) with a power of $90 \%$. Data were analyzed for normality using the Shapiro-Wilk test. The Lee index variable was parametric, and two-way ANOVA test with Dunn's post-hoc 
Costa et al.: Satietogenic Protein from Tamarind Seeds Decreases Food Intake, Leptin Plasma and CCK-1r Gene Expression in Obese Wistar Rats

Table 1. Plasma CCK of the obese and lean Wistar rats in the four studied groups after the 10-day experiment

\begin{tabular}{ll}
\hline Groups & $\begin{array}{l}\text { Plasma CCK, ng/mL } \\
\text { mean (dp) }\end{array}$ \\
\hline Lean/standard diet & $2.46(0.15)$ \\
Obese/HGLI diet & $2.39(0.19)$ \\
Obese/standard diet & $2.43(0.29)$ \\
Obese/HGLI diet + TTI & $2.71(0.28)$ \\
\hline \multicolumn{2}{c}{ Groups: Standard diet + 1 mL of water by gavage (lean/ standard } \\
diet); high glycemic index and load diet +1 mL of water by gavage \\
(obese/HGLI diet); Standard diet +1 mL water by gavage (obese/ \\
standard diet); high glycemic index and load diet +1 mL of TTI at 25 \\
mg/kg by gavage (obese/HGLI diet + TTI). HGLI diet: mixture composed \\
of Labina ${ }^{\circledR}$, condensed milk and sugar (1:1:0.21); Standard diet: \\
Labina ${ }^{\circledR}$ chow. TTI, Tamarindus indica L. seed-isolated trypsin inhibitor. \\
Kruskal-Walls test with Dunn's post-hoc test, $p>0.05$.
\end{tabular}

test was used to verify differences between studied groups. The food intake, plasma CCK, and leptin variable were nonparametric, and Kruskal-Wallis with Dunn's post-hoc test was used. Differences between the relative mRNA expression were tested using the Mann-Whitney test. Graph Pad Prism, version 5.0 (Graph Pad Software, San Diego, CA, USA), was used for statistical analyses. For all analyses, $p$ values of less than 0.05 were considered significant.

\section{Results}

\section{TTI Isolation with Affinity Chromatography on Trypsin-Sepharose}

TTI showed $39700.58 \mathrm{IU} / \mathrm{mg}$ of protein and 100\% inhibition for trypsin. TTI isolation was confirmed by $12.5 \%$ SDS-PAGE, with a protein band of approximately $20 \mathrm{kDa}$.

\section{TTI Effect on the Food Intake and Lee Index}

According to Figure 1A, obese animals treated with TTI decreased food intake in a similar way as lean animals. Interestingly, obese animals treated with TTI when compared to those with no treatment, reduced food intake $(p=0.0127)$ but, in all the other groups the food intake is statistically equal. As shown in Figure 1B, lean animals maintained the zoometric measurements during the 10 days of the experiment. All studied animals in the three other groups were obese from the beginning to the end of the experiment. Although not significant, obese animals treated with TTI showed a slight reduction of the Lee index, even if they were fed with the HGLI diet.

TTI Effect on Plasma CCK and Relative mRNA Expression of Intestinal CCK-Related Genes

TTI did not increase plasma CCK in obese animals; Table 1 shows the plasma values of CCK for the four groups analyzed in the study. Relative mRNA expression of the pre-pro-CCK, $C C K-2 R$ and PCSK1 genes involved in CCK secretion did not change in response to TTI treatment in obese animals (Fig. 2A, C, D). The relative mRNA expression of CCK-1R significantly decreased in response to TTI in obese animals when compared to obese animals with no treatment ( $p=0.027$ ) (Fig. 2B). In obese animals, the standard diet also decreased the relative mRNA CCK-1R expression to values even lower than those found in the lean animals $(p=$ 0.027) (Fig. 2B). Moreover, the standard diet reduced mRNA pre-pro-CCK in the obese animals when compared to those with no treatment and those that received TTI (Fig. 2A). 
Costa et al.: Satietogenic Protein from Tamarind Seeds Decreases Food Intake, Leptin

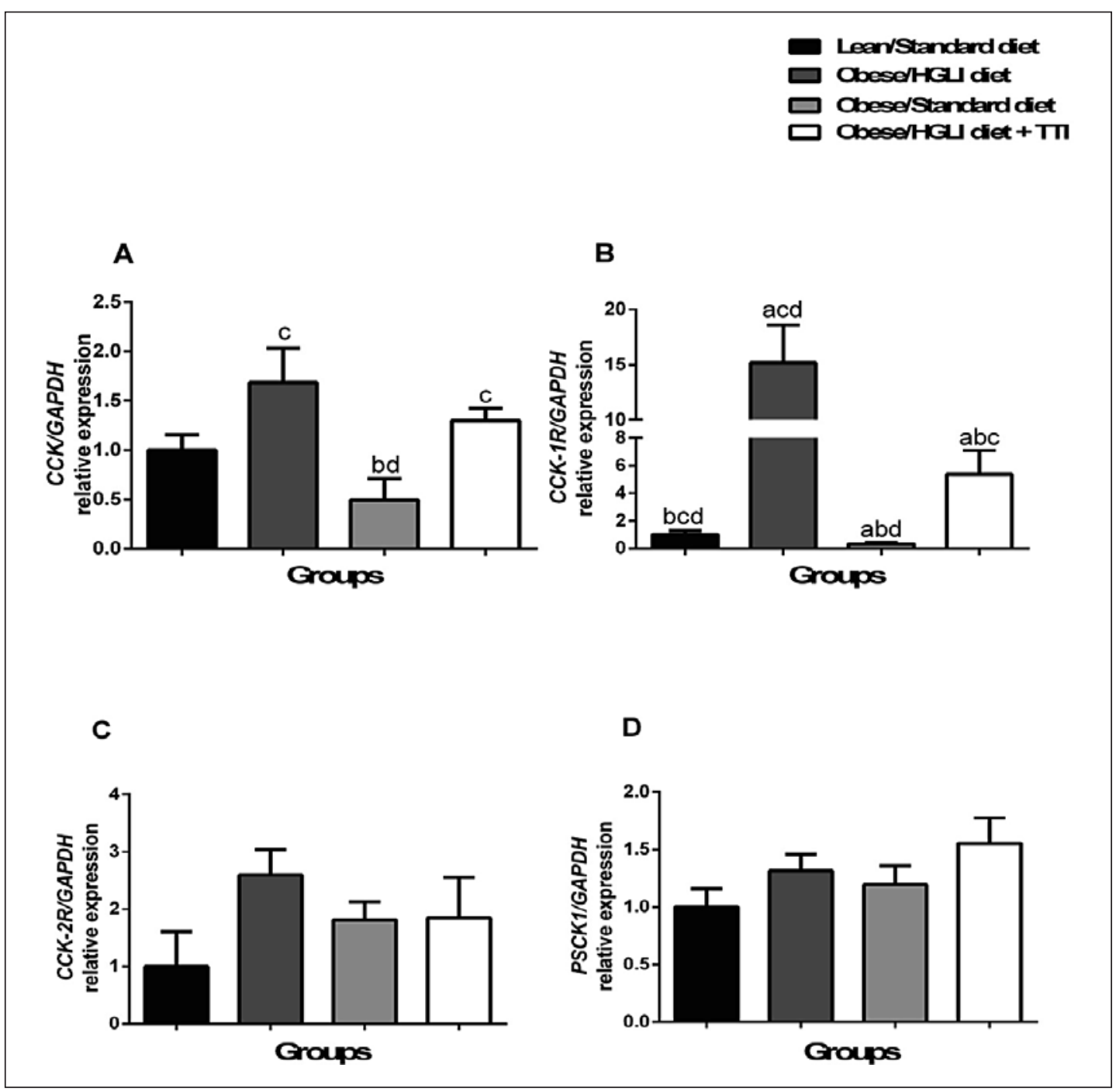

Fig. 2. Relative mRNA expression of genes involved with CCK in the intestine of obese and lean Wistar rats in the four studied groups after the 10-day experiment. Groups: standard diet $+1 \mathrm{~mL}$ of water by gavage (lean/ standard diet); high glycemic index and load diet $+1 \mathrm{~mL}$ of water by gavage (obese/HGLI diet); standard diet $+1 \mathrm{~mL}$ water by gavage (obese/standard diet); high glycemic index and load diet $+1 \mathrm{~mL}$ of TTI at $25 \mathrm{mg} / \mathrm{kg}$ by gavage (Obese/HGLI diet + TTI). HGLI diet: mixture composed of Labina ${ }^{\circledR}$, condensed milk and sugar (1:1: 0.21); Standard diet: Labina ${ }^{\circledR}$ chow. TTI, Tamarindus indica L. seed Isolated Trypsin Inhibitor. CCK, Pre-proCholecystokinin; PCSK1, pro protein convertase subtilisin/kexin1; CCK-1R, type 1 CCK receptor; CCK-2R, type 2 CCK receptor and GAPDH: glyceraldehyde-3-phosphate dehydrogenase. Mann-Whitney test was used to compare the studied groups. Mann-Whitney test was used to compare the studied groups. Letters indicate $p$ $<0.05$, a: comparing with the lean/standard diet group; b: comparing with the obese/HGLI diet group; c: comparing with the Obese/Standard diet group; $\mathbf{d}$ : comparing with the obese/HGLI diet + ITT group.

\section{TTI Effect on Plasma Leptin and Relative mRNA Expression of the ob Gene in the}

Subcutaneous Adipose Tissue

Lean animals in the standard diet presented the lowest mean plasma leptin concentrations, as expected ( $p=0.027)$. We observed that $60 \%$ of the obese animals receiving TTI ( $n=$ $3)$ had very low leptin concentrations under the minimum detection concentration $(<0.1$ $\mathrm{ng} / \mathrm{mL}$ ). Thus, only two obese animals presented with detectable plasma leptin of $0.2 \mathrm{ng} / \mathrm{mL}$ 
Table 2. Plasma leptin of the obese and lean Wistar rats in the four studied groups after the 10-day experiment
Costa et al.: Satietogenic Protein from Tamarind Seeds Decreases Food Intake, Leptin Plasma and CCK-1r Gene Expression in Obese Wistar Rats

\begin{tabular}{ll} 
Groups & $\begin{array}{l}\text { Plasma lepti } \\
\text { mean (dp) }\end{array}$ \\
\hline Lean/Standard diet & $0.15(0.06)^{\#}$ \\
Obese/HGLI diet & $0.54(0.11)$ \\
Obese/Standard diet & $0.48(0.19)^{\#}$ \\
Obese/HGLI diet + TTI & $0.20^{\# \#}$
\end{tabular}

${ }^{\#} n=1$ animal under the detection concentration $(0.1 \mathrm{ng} / \mathrm{mL})$. ${ }^{\# \#} n=3$ animals in this group under the detection concentration $(0.1$ $\mathrm{ng} / \mathrm{mL}$ ); standard deviation was not calculated. Dunn's post-hoc test indicated significant a difference between the lean/standard diet and obese/HGLI diet. Groups: standard diet $+1 \mathrm{~mL}$ of water by gavage (lean/standard diet); high glycemic index and load diet $+1 \mathrm{~mL}$ of water by gavage (obese/HGLI diet); Standard diet $+1 \mathrm{~mL}$ water by gavage (obese/standard diet); high glycemic index and load diet $+1 \mathrm{~mL}$ of TTI at $25 \mathrm{mg} / \mathrm{kg}$ by gavage (obese/HGLI diet + TTI). HGLI diet: mixture composed of Labina ${ }^{\circledR}$, condensed milk and sugar (1:1:0.21); Standard diet: Labina ${ }^{\circledR}$ chow. TTI: Tamarindus indica L. seed- isolated trypsin inhibitor. Kruskal-Walls test with Dunn's post-hoc test, $p=0.027$.

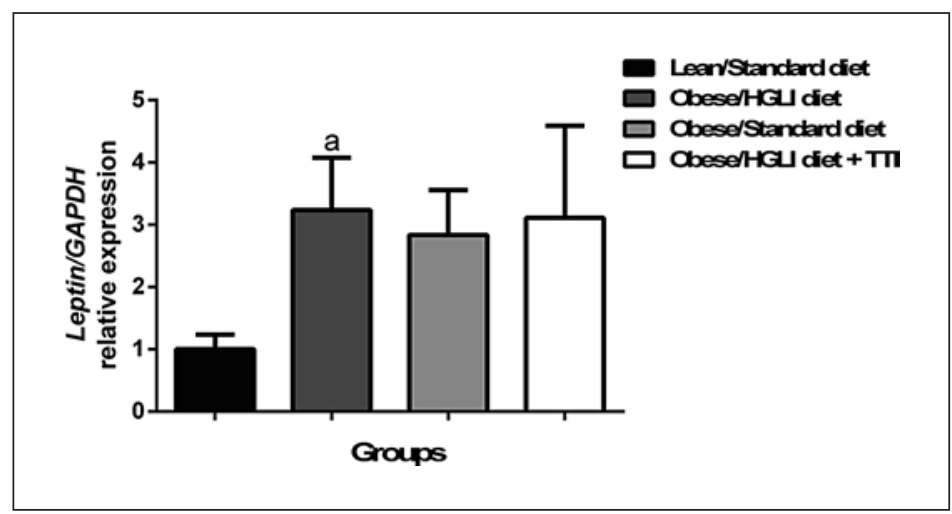

Fig. 3. Relative mRNA expression of the leptin $o b$ gene in subcutaneous fat in obese and lean Wistar rats in the four groups studied after 10 days of experiment. Groups: standard diet $+1 \mathrm{~mL}$ of water by gavage (lean/ standard diet); high glycemic index and load diet $+1 \mathrm{~mL}$ of water by gavage (obese/HGLI diet); standard diet $+1 \mathrm{~mL}$ water by gavage (obese/standard diet); high glycemic index and load diet $+1 \mathrm{~mL}$ of TTI at $25 \mathrm{mg} / \mathrm{kg}$ by gavage (obese/HGLI diet + TTI). HGLI diet: Mixture composed of Labina ${ }^{\circledR}$, condensed milk and sugar (1: 1:0.21); Standard diet: Labina ${ }^{\circledR}$ chow. TTI, Tamarindus indica L. seed-isolated trypsin inhibitor. Mann-Whitney test was used to compare the studied groups. Letters indicate $p<0.05$, a: comparing with the lean/standard diet group; b: comparing with the obese/HGLI diet group; c: comparing with the obese/standard diet group; d: comparing with the Obese/HGLI diet + ITT group.

of this hormone, which is also very low, but detectable by the test utilized. Thus, comparison of the mean plasma leptin concentrations between studied groups is unfeasible. In contrast, $100 \%$ of the obese animals receiving the HGLI diet had plasma leptin above the detection concentrations (Table 2).

There was no significant effect of the tested diets/treatments on the relative mRNA expression of the leptin $o b$ gene from subcutaneous fat (Fig. 3). As expected, lean animals presented a significantly lower relative mRNA expression of the leptin ob gene when compared to the obese animals with no treatment $(p=0.021)$. 
Costa et al.: Satietogenic Protein from Tamarind Seeds Decreases Food Intake, Leptin Plasma and CCK-1r Gene Expression in Obese Wistar Rats

\section{Discussion}

Previous studies conducted by our group demonstrated that TTI has a satietogenic and anti-inflammatory effect $[28,29]$. We isolated TTI from tamarind seeds and observed the same inhibitory and molecular mass characteristics as reported previously by Ribeiro et al. [28] and Carvalho et al. [29]. We administered TTI to a group of obese animals fed with a HGLI diet and compared this group with obese animals under conventional treatment (standard diet), with obese animals without treatment (maintaining the HGLI diet), and with lean animals receiving standard diet. In the present study, the Lee index, resembling human BMI, was used [35] as a standard for the diagnosis of nutritional status assessment [2].

On the first and last days of the experiment food intake and zoometric measurements of all animals were done. In 10 days of experiment, TTI decreased food intake of obese animals when compared to those with no treatment, confirming the findings of the study of Carvalho et al. [29] who already showed that TTI had reduced food intake even when obese animals were offered an unbalanced diet causing obesity and its associated comorbidities.

In addition, after 10 days we observed that lean and obese animals maintained their previous nutritional zoometric status. However, animals receiving TTI showed a discrete reduction in weight gain, probably due reductions of the food intake, and, consequently, a slight decrease in the Lee index, while animals in the other groups tended to continue increasing weight. Sprague-Dawley rats with diet-induced obesity treated with exogenous CCK-8 showed weight reduction only after 23 days of experimentation [41]. Accordingly, we hypothesize that, with a more extended treatment period, reduction of the Lee index would be more consistent.

In the present study, we also evaluated plasma CCK and the relative mRNA expression of essential genes to its production in order to test if TTI could increase plasma CCK in obese animals, as previously observed in eutrophic animals [28]. However, TTI did not increase plasma CCK in obese animals.

Studies with obese rats have shown that these animals present CCK resistance, whereas eutrophic animals present regular production and response to CCK. Interestingly, although obese animals presented reduced sensitivity to the satietogenic effect of CCK, they maintained the sensitivity to other CCK functions such as gastric emptying and intestinal transit $[42,43]$. However, data on CCK secretagogues and mRNA expression of CCK-related genes in obese rats are not yet available.

In the present study, the relative mRNA expression of CCK-related genes was evaluated. We found no effect of TTI on the relative mRNA expression of PCSK1 and CCK-2R genes. Moreover, when analyzing the relative mRNA expression of $C C K-1 R$, we observed that obese animals treated with standard diet significantly showed a reduced relative mRNA expression of this gene when compared to the other obese animals. TTI was also able to decrease $C C K-1 R$ relative mRNA gene expression in obese animals when compared to those with no treatment. To our knowledge, there are no other studies in obese animals investigating genes involved in CCK secretion.

Barrachina et al. [20] suggested the existence of a functional synergistic interaction between leptin and CCKleading to early suppression of food intake involving CCK-1R receptors and activation of capsaicin-sensitive afferent fibers sending signals to paraventricular nucleus of the hypothalamus neurons as part of the central neural pathway underlying the mechanism of action of leptin-CCK interaction.

These results suggest that the CCK-1R receptor in the intestine may also be involved in leptin-CCK-induced food suppression as previously established for the CCK-1R receptor in vagal afferent fibers $[20,42,44,45]$. Future studies on TTI should clarify whether or TTI treatment activates vagal afferent neurons. 
Costa et al:: Satietogenic Protein from Tamarind Seeds Decreases Food Intake, Leptin Plasma and CCK-1r Gene Expression in Obese Wistar Rats

Among studies with trypsin inhibitors, only the study of Komarnytsky et al. [32] observed duodenal CCK postprandial mRNA expression. In this study, eutrophic Wistar rats were treated with protease inhibitors from potato and presented, in accordance with the observed plasma increase in CCK, a 2.4-fold increase in pre-pro-CCK (Genbank X01032) when compared to the control group. This finding was in contrast our data as we did not find any difference in pre-pro-CCK relative mRNA expression in response to TTI in obese animals.

By analyzing the data presented, we hypothesize that obesity influences the TTI effect upon CCK resulting in divergent results in eutrophic and obese rats with respect to plasma concentrations and the relative mRNA expression of the genes involved in CCK production. Studies with nutritionally unbalanced diets, offered for extended periods to animals with or without obesity, have demonstrated a reduction in the sensitivity to satiety hormones, including GLP-1 and CCK in addition to a postprandial decrease in their circulating concentrations $[43,46]$.

It is known that trypsin inhibitors cause a reduction in food intake and consequently induce weight loss in eutrophic animals, even when given for short periods. These effects are commonly attributed to a secretagogue effect upon CCK [28, 31-34].

Unfortunately, in obese animals, these effects do not seem to be the same, given the resistance and/or decrease in the secretion or action of CCK caused by the excessive increase of adipose tissue $[11,42]$. Nevertheless, in the present study, TTI decreased food intake within 10 days of the experiment.

The influence of obesity on the secretion of hormones that act on the modulation of the CCK response, e.g. leptin, is still controversially discussed [20,21]. There seems to be a close synergetic relationship between the effect of CCK and the concentration of leptin in obese animals [18-21, 47-49].

We therefore also investigated in the present study if TTI has an effect upon on plasma leptin concentrations and on the mRNA expression of the $o b$ gene. We expected that obese animals presented with high leptin plasma concentrations, since obesity commonly leads to hyperleptinemia [12]. Accordingly, we observed that lean animals (lean/standard diet) consuming a nutritionally adequate diet had low concentrations of plasma leptin) very close to the minimum value detectable by the method used. In untreated obese animals (obese/ HGLI diet) leptin concentrations were at about four times higher than in lean animals. These findings corroborate studies in obese humans and rodents showing that leptin concentrations in obese subjects can be five times higher than in lean subjects [50,51]. In $60 \%$ of animals treated with TTI (obese/HGLI diet + TTI), leptin concentrations were under the detection limit, and in the remaining $40 \%$ they were considerably lower than in obese (HGLI diet group) which is an interesting result as these animals were still obese and consumed an obese/HGLI diet (the diet that was used to induce and maintain obesity in the experimental animals). Moreover, only $20 \%$ of obese animals submitted to the standard diet reduced plasma leptin to undetectable concentrations. Surprisingly, a substance known to stimulate CCK production (TTI) is thus more effective in reducing leptin plasma levels than the conventional treatment of obesity by standard diet. Carvalho et al. [29] showed that TTI reduced TNF- $\alpha$ levels, which, like leptin, is also produced by fat tissue, regardless of whether weight loss occurred or not.

One of the limitations of the present study is that we only determined the nutritional status assessment, and not adiposity. By determining adiposity, the characterization of the relationships between lipogenesis and reduction of leptin would be even clearer. Further studies should focus on that.

TTI was able to reduce plasma leptin but did not reduce the relative mRNA expression of the $o b$ gene when compared with the obese group with no treatment. Nevertheless, obese animals treated with standard diet and with HGLI diet plus TTI showed no significant differ- 
ences in the expression of this gene compared to lean animals. The action of TTI might explain this plasma reduction on genes that are involved in other pathways regulating leptin expression, post-transcriptional changes or even act on the leptin receptor.

Also studies with hormones showed divergences between plasma and expression values, especially when involving a single candidate gene, given the complexity in the regulation of expression. A study evaluating the sensitivity of obese animals to peptide YY (PYY) and glucagon-like peptide-1 (GLP-1) found plasma reductions of these hormones, which was not corroborated by gene expression [52]. Concerning leptin, little is known about the transcription pathways that regulate its specific expression in adipocytes [53].

Matson et al. [21] suggested the search for strategies to decrease the effects of leptin in resistant obese individuals, which is the way to improve the efficiency of CCK in weight reduction. This effect is not entirely dependent on the eating behavior but on a synergistic effect of the peripheral action of CCK and the of central action of leptin.

In a study to analyze leptin resistance in the afferent vagal nerve (AVN) in DIO Zucker rats [19], the authors found that leptin resistance in the AVN was also associated with a reduced sensibility to CCK, thus altering the expression of receptors related to satiety in the AVN. The authors suggested that this was a result of increased signaling to orexigenic pathways and decreased signaling from intestinal anorexic hormones, finally leading to hyperphagia [19].

Additionally, Buyse et al. [54] indicated that vagal leptin receptors in the stomach may be activated by locally produced leptin and may serve to increase postprandial satiety induced by the CCK-1R. Leptin is considered to promote CCK-1R uptake via increased gene expression of the $C C K-1 R$. Thus, amelioration of hyperleptinemia by TTI could also cause a down-regulation of mRNA expression of $C C K-1 R$.

Another hypothesis that can be raised by the present results is that TTI can act as a hormone, binding to specific receptors and stimulating the production of anorexigenic neuropeptides. A bioactive peptide (trypsin inhibitor) with hypoglycemic action was observed in Momordica charantia (bitter melon) [55]. This peptide presents 68 amino acid residues and the insulin receptor binding protein of $M$. charantia (mcIRBP). It acts by activating insulin receptor signaling pathways and stimulating both the uptake and release of glucose in rat cells $[56,57]$. Confirming these data, mcIRBP-19 was observed to be the peptide insulin receptor binding motif of mcIRBP with a similar ability for glucose uptake [58].

The present study investigating with the relative mRNA expression of intestinal CCKrelated genes in obese rats is in agreement with several studies and considering the synergism of CCK and leptin in the control of appetite. We believe that the reduction of food intake in obese animals induced by TTI, as observed in the present study and in the study by Carvalho et al. [29], is the result of a TTI-dependent decrease of plasma leptin to values even lower than those detected in lean animals. Both studies demonstrated that TTI might have effects that are comparable to those induced by a standard, nutritionally adequate diet. The results are particularly interesting as TTI was administered to obese animals still consuming the HGLI diet, which is unbalanced.

To the best of our knowledge, this is the first report investigating the effects of a trypsin inhibitor on plasma CCK and mRNA expression of key genes related to CCK expression in obese animals. Our data suggests that TTI, by decreasing plasma leptin, improves CCK action, regardless of its increased values in plasma of obese rats, since food intake and CCK-1R expression were lower in the TTI-treated group when compared with no-treatment group. Therefore, the effects of TTI should be further investigated in obese models

Translating a standard experimental diet to a balanced clinical diet for obese humans is difficult, as obese individuals may be reluctant in changing food habits. Thus, TTI, after successfully passing further animal studies, might be investigated as a therapy adjuvant, which may help to improve hormone production related to satiety. 
Costa et al.: Satietogenic Protein from Tamarind Seeds Decreases Food Intake, Leptin

Plasma and CCK-1r Gene Expression in Obese Wistar Rats

\section{Grants}

This work received the financial support of the Fundação de Apoio à Pesquisa do Rio Grande do Norte (FAPERN/Award Number: 0887/2015) research promotion agencies Brazilian. The student received scholarship of the Coordenação de Aperfeiçoamento de Pessoal de Nível Superior (CAPES).

\section{Disclosure Statement}

The authors declare no conflict of interest.

\section{References}

1 GBD 2015 Obesity Collaborators, Afshin A, Forouzanfar MH, Reitsma MB, Sur P, Estep K, Lee A, et al. The GBD 2015 obesity collaborators. Health effects of overweight and obesity in 195 countries over 25 years. N Engl J Med. 2017 Jul;377(1):13-27.

2 Associação Brasileira para o Estudo da Obesidade e da Síndrome Metabólica. Ganho de peso e obesidade: etiologia. Diretrizes brasileiras de obesidade 2016/ABESO. São Paulo: ABESO; 2016.

3 World Health Organization. Obesity and overweight: fact sheet. Available from: http://www.who.int/mediacentre/factsheets/fs311/en/

4 Dockray GJ. Gastrointestinal hormones and the dialogue between gut and brain. J Physiol. 2014 Jul;592(14): 2927-41.

5 Gagnon J, Mayne J, Mbikay M, Woulfe J, Chrétien M. Expression of PCSK1 (PC1/3), PCSK2 (PC2) and PCSK3 (furin) in mouse small intestine. Regul Pept. 2009 Jan;152(1-3):54-60.

6 Reeve JR Jr, Eysselein V, Walsh JH, Ben-Avram CM, Shively JE. New molecular forms of cholecystokinin. Microsequence analysis of forms previously characterized by chromatographic methods. J Biol Chem. 1986 Dec; 261(35):16392-7.

7 Eysselein VE, Eberlein GA, Hesse WH, Schaeffer M, Grandt D, Williams R, et al. Molecular variants of cholecystokinin after endogenous stimulation in humans: a time study. Am J Physiol. 1990 Jun;258(6 Pt 1):G951-7.

8 Sayegh AI, Washington MC, Johnson RE, Johnson-Rouse T, Freeman C, Harrison A, et al. Celiac and the cranial mesenteric arteries supply gastrointestinal sites that regulate meal size and intermeal interval length via cholecystokinin-58 in male rats. Horm Behav. 2015 Jan;67:48-53.

9 Sayegh AI. The role of cholecystokinin receptors in the short-term control of food intake. Prog Mol Biol Trans Sci. 2013;114:277-316.

10 Triantafyllou GA, Paschou SA, Mantzoros CS. Leptin and Hormones: energy Homeostasis. Endocrinol Metab Clin North Am. 2016 Sep;45(3):633-45.

11 Duca FA, Zhong L, Covasa M. Reduced CCK signaling in obese-prone rats fed a high fat diet. Horm Behav. 2013 Nov;64(5):812-7.

12 Sáinz N, Barrenetxe J, Moreno-Aliaga MJ, Martínez JA. Leptin resistance and diet-induced obesity: central and peripheral actions of leptin. Metabolism. 2015 Jan;64(1):35-46.

13 McLaughlin CL, Baile CA, Buonomo FC. Effect of CCK antibodies on food intake and weight gain in Zucker rats. Physiol Behav. 1985 Feb;34(2):277-82.

14 McLaughlin CL, Baile CA. Decreased sensitivity of Zucker obese rats to the putative satiety agent cholecystokinin. Physiol Behav. 1980 Oct;25(4):543-8.

15 McLaughlin CL, Peikin SR, Baile CA. Food intake response to modulation of secretion of cholecystokinin in Zucker rats. Am J Physiol. 1983 May;244(5):R676-85.

16 Sandoval DA, Davis SN. Leptin: metabolic control and regulation. J Diabetes Complications. 2003 Mar-Apr; 17(2):108-13.

17 Gomez G, Englander EW, Greeley GH Jr. Nutrient inhibition of ghrelin secretion in the fasted rat. Regul Pept. 2004 Jan;117(1):33-6.

18 Peters JH, Karpiel AB, Ritter RC, Simasko SM. Cooperative activation of cultured vagal afferent neurons by leptin and cholecystokinin. Endocrinology. 2004 Aug;145(8):3652-7.

19 De Lartigue G, Serre CB, Espero E, Lee J, Raybould HE. Leptin resistance in vagal afferent neurons inhibits cholecystokinin signaling and satiation in diet induced obese rats. PLoS One. 2012; 7(2):e32967.

20 Barrachina MD, Martínez V, Wang L, Wei JY, Taché Y. Synergistic interaction between leptin and cholecystokinin to reduce short-term food intake in lean mice. Proc Natl Acad Sci USA. 1997 Sep;94(19):10455-60.

21 Matson CA, Reid DF, Cannon TA, Ritter RC. Cholecystokinin and leptin act synergistically to reduce body weight. Am J Physiol Regul Integr Comp Physiol. 2000 Apr;278(4):R882-90.

22 Xu X, Wang J, Li L, Wang C, Li W, Zhang Q, et al. The role of obestatin in Roux-en-Y gastric bypass surgery in the obese, type 2 diabetes Zucker rat. Diabetes Res Clin Pract. 2016 Sep;119:57-64.

23 Zucker LM, Zucker TF. Fatty, a new mutation in the rat. J Hered. 1961;52(6):275-8. 
Costa et al.: Satietogenic Protein from Tamarind Seeds Decreases Food Intake, Leptin

Plasma and CCK-1r Gene Expression in Obese Wistar Rats

24 Lubrano-Berthelier C, Cavazos M, Dubern B, Shapiro A, Stunff CL, Zhang S, et al. Molecular genetics of human obesity-associated MC4R mutations. Ann N Y Acad Sci. 2003 Jun;994(1):49-57.

25 Kamalakkannan S, Tirupathi Pichiah PB, Kalaiselvi S, Arunachalam S, Achiraman S. Emu oil decreases atherogenic plaque formation in cafeteria diet-induced obese rats. J Sci Food Agric. 2016 Jul;96(9):3063-8.

26 Moncada R, Rodríguez A, Becerril S, Méndez-Giménez L, Valentí V, Ramírez B, et al. Sleeve Gastrectomy Decreases Body Weight, Whole-Body Adiposity, and Blood Pressure Even in Aged Diet-Induced Obese Rats. Obes Surg. 2016 Jul;26(7):1549-58.

27 Scott CJ, Taggart CC. Biologic protease inhibitors as novel therapeutic agents. Biochimie. 2010 Nov; $92(11)$ : 1681-8.

28 Ribeiro JA, Serquiz AC, Silva PF, Barbosa PB, Sampaio TB, Araújo RF Junior, et al. Tamarindus indica L. seed trypsin inhibitor reduce weight gain, food consumption and increases plasmatic cholecystokinin levels. Clinics (São Paulo). 2015;70(2):136-43.

29 Carvalho FM, Lima VC, Costa IS, Medeiros AF, Serquiz AC, Lima MC, et al. A Trypsin Inhibitor from Tamarind Reduces Food Intake and Improves Inflammatory Status in Rats with Metabolic Syndrome Regardless of Weight Loss. Nutrients. 2016 Sep;8(10):1-14.

30 Spannagel AW, Green GM, Guan D, Liddle RA, Faull K, Reeve JR Jr. Purification and characterization of a luminal cholecystokinin-releasing factor from rat intestinal secretion. Proc Natl Acad Sci USA. 1996 Apr;93(9):441520.

31 Chen H, Charlat O, Tartaglia LA, Woolf EA, Weng X, Ellis SJ, et al. Evidence that the diabetes gene encodes the leptin receptor: identification of a mutation in the leptin receptor gene in $\mathrm{db} / \mathrm{db}$ mice. Cell. $1996 \mathrm{Feb}$;84(3): 491-5.

32 Komarnytsky S, Cook A, Raskin I. Potato protease inhibitors inhibit food intake and increase circulating cholecystokinin levels by a trypsin-dependent mechanism. Int J Obes. 2011 Feb;35(2):236-43.

33 Nakajima S, Hira T, Tsubata M, Takagaki K, Hara H. Potato extract (Potein) suppresses food intake in rats through inhibition of luminal trypsin activity and direct stimulation of cholecystokinin secretion from enteroendocrine cells. J Agric Food Chem. 2011 Sep;59(17):9491-6.

34 Serquiz AC, Machado RJ, Serquiz RP, Lima VC, de Carvalho FM, Carneiro MA, et al. Supplementation with a new trypsin inhibitor from peanut is associated with reduced fasting glucose, weight control, and increased plasma CCK secretion in an animal model. J Enzyme Inhib Med Chem. 2016 Dec;31(6):1261-9.

35 Bernardis LL, Patterson BD. Correlation between 'Lee index' and carcass fat content in weanling and adult female rats with hypothalamic lesions. J Endocrinol. 1968 Apr;40(4):527-8.

36 Kakade ML, Simons N, Liener IE. An evaluation of natural vs. Synthetic substrates for measuring the antitryptic activity of soybean samples. Cereal Chem. 1969;46:518-26.

37 Bradford MM. A rapid and sensitive method for the quantitation of microgram quantities of protein utilizing the principle of protein-dye binding. Anal Biochem. 1976 May;72(1-2):248-54.

38 Laemmli UK. Cleavage of structural proteins during the assembly of the head of bacteriophage T4. Nature. 1970 Aug;227(5259):680-5.

39 Novelli EL, Diniz YS, Galhardi CM, Ebaid GM, Rodrigues HG, Mani F, et al. Anthropometrical parameters and markers of obesity in rats. Lab Anim. 2007 Jan;41(1):111-9.

40 Livak KJ, Schmittgen TD. Analysis of relative gene expression data using real-time quantitative PCR and the 2(-Delta Delta C(T)) Method. Methods. 2001 Dec;25(4):402-8.

41 Mhalhal TR, Washington MC, Newman K, Heath JC, Sayegh AI. Infusion of exogenous cholecystokinin-8, gastrin releasing peptide- 29 and their combination reduce body weight in diet-induced obese male rats. Appetite. 2017 Feb;109:172-81.

42 Moos AB, McLaughlin CL, Baile CA. Effects of CCK on gastrointestinal function in lean and obese Zucker rats. Peptides. 1982 Jul-Aug;3(4):619-22.

43 Niederau C, Meereis-Schwanke K, Klonowski-Stumpe H, Herberg L. CCK-resistance in Zucker obese versus lean rats. Regul Pept. 1997 Jun; 70(2-3):97-104.

44 Miyasaka K, Kanai S, Ohta M, Kawanami T, Kono A, Funakoshi A. Lack of satiety effect of cholecystokinin (CCK) in a new rat model not expressing the CCK-A receptor gene. Neurosci Lett. 1994 Oct;180(2):143-6.

45 Silver AJ, Flood JF, Song AM, Morley JE. Evidence for a physiological role for CCK in the regulation of food intake in mice. Am J Physiol. 1989 Mar;256(3 Pt 2):R646-52.

46 Williams DL, Hyvarinen N, Lilly N, Kay K, Dossat A, Parise E, et al. Maintenance on a high-fat diet impairs the anorexic response to glucagon-like-peptide-1 receptor activation. Physiol Behav. 2011 Jul;103(5):557-64.

47 de Lartigue G, Barbier de la Serre C, Espero E, Lee J, Raybould HE, Raybould HE. Diet-induced obesity leads to the development of leptin resistance in vagal afferent neurons. Am J Physiol Endocrinol Metab. 2011 Jul; 301(1):E187-95.

48 de Lartigue G, Lur G, Dimaline R, Varro A, Raybould H, Dockray GJ. EGR1 Is a target for cooperative interactions between cholecystokinin and leptin, and inhibition by ghrelin, in vagal afferent neurons. Endocrinology. 2010 Aug;151(8):3589-99.

49 Wang L, Barachina MD, Martínez V, Wei JY, Taché Y. Synergistic interaction between CCK and leptin to regulate food intake. Regul Pept. 2000 Aug;92(1-3):79-85.

50 Ostlund RE Jr, Yang JW, Klein S, Gingerich R. Relation between plasma leptin concentration and body fat, gender, diet, age, and metabolic covariates. J Clin Endocrinol Metab. 1996 Nov;81(11):3909-13. 
Costa et al.: Satietogenic Protein from Tamarind Seeds Decreases Food Intake, Leptin Plasma and CCK-7r Gene Expression in Obese Wistar Rats

51 Maffei M, Halaas J, Ravussin E, Pratley RE, Lee GH, Zhang Y, et al. Leptin levels in human and rodent: measurement of plasma leptin and ob RNA in obese and weight-reduced subjects. Nat Med. 1995 Nov;1(11): 1155-61.

52 Duca FA, Swartz TD, Sakar Y, Covasa M. Decreased intestinal nutrient response in diet-induced obese rats: role of gut peptides and nutrient receptors. Int J Obes. 2013 Mar;37(3):375-81.

53 Wrann CD, Rosen ED. New insights into adipocyte-specific leptin gene expression. Adipocyte. 2012 Jul;1(3): 168-72.

54 Buyse M, Ovesjö ML, Goïot H, Guilmeau S, Péranzi G, Moizo L, et al. Expression and regulation of leptin receptor proteins in afferent and efferent neurons of the vagus nerve. Eur J Neurosci. 2001 Jul;14(1):64-72.

55 Singh J, Cumming E, Manoharan G, Kalasz H, Adeghate E. Medicinal chemistry of the anti-diabetic effects of momordica charantia: active constituents and modes of actions. Open Med Chem J. 2011;5 Suppl 2:70-7.

56 Lo HY, Ho TY, Li CC, Chen JC, Liu JJ, Hsiang CY. A novel insulin receptor-binding protein from Momordica charantia enhances glucose uptake and glucose clearance in vitro and in vivo through triggering insulin receptor signaling pathway. J Agric Food Chem. 2014 Sep;62(36):8952-61.

57 Lo HY, Ho TY, Lin C, Li CC, Hsiang CY. Momordica charantia and its novel polypeptide regulate glucose homeostasis in mice via binding to insulin receptor. J Agric Food Chem. 2013 Mar;61(10):2461-8.

58 Lo HY, Li CC, Ho TY, Hsiang CY. Identification of the bioactive and consensus peptide motif from Momordica charantia insulin receptor-binding protein. Food Chem. 2016 Aug;204:298-305. 